\title{
Clinical decision-making and therapeutic approaches in osteopathy - A qualitative grounded theory study
}

\author{
Oliver P. Thomson, Nicola J. Petty, Ann P. Moore
}

\author{
$\mathrm{a} b \mathrm{~s} t \mathrm{r}$ a c t
}

There is limited understanding of how osteopaths make decisions in relation to clinical practice. The aim of this research was to construct an explanatory theory of the clinical decision-making and therapeutic approaches of experienced osteopaths in the UK.

Twelve UK registered osteopaths participated in this constructivist grounded theory qualitative study. Purposive and theoretical sampling was used to select participants. Data was collected using semistructured interviews which were audio-recorded and transcribed. As the study approached theoretical sufficiency, participants were observed and video-recorded during a patient appointment, which was followed by a video-prompted interview. Constant comparative analysis was used to analyse and code data.

Data analysis resulted in the construction of three qualitatively different therapeutic approaches which characterised participants and their clinical practice, termed; Treater, Communicator and Educator. Participants' therapeutic approach influenced their approach to clinical decision-making, the level of patient involvement, their interaction with patients, and therapeutic goals. Participants' overall conception of practice lay on a continuum ranging from technical rationality to professional artistry, and contributed to their therapeutic approach. A range of factors were identified which influenced participants' conception of practice.

The findings indicate that there is variation in osteopaths' therapeutic approaches to practice and clinical decision-making, which are influenced by their overall conception of practice. This study provides the first explanatory theory of the clinical decision-making and therapeutic approaches of osteopaths.

Keywords:

Clinical reasoning Decision-making Osteopathy Grounded theory

\section{Introduction}

Currently, the number of osteopaths in the UK exceeds 4500 (GOsC, 2012b) and practitioners are increasingly being considered as significant providers of manual therapy (NICE, 2009). Osteopaths in the UK are autonomous practitioners who diagnose and manage patients with a range of musculoskeletal conditions (Fawkes et al., 2010). Practitioners employ an array of therapeutic interventions, with 'hands-on' manipulative techniques (e.g. spinal manipulation) preferred by practitioners in the UK (Fawkes et al., 2010) and internationally (Johnson and Kurtz, 2003; Orrock, 2009).

Osteopathic practise is considered to be patient-centred (WHO, 2010; GOsC, 2012b) and underpinned by a core set of principles, concepts and theories, many of which focus on the anatomical and physiological capabilities of the human body (Seffinger et al., 2003; Paulus, 2013). Currently osteopaths tend to be defined by their application of techniques, such as treatment applied to the: neuromusculoskeletal system often termed 'structural osteopathy' (Hartman, 1996); internal organs, termed 'visceral osteopathy' (Hebgen, 2010) and applied to the skull, termed 'cranial osteopathy' (Liem et al., 2004). Although these characterisations provide some useful description of the therapeutic techniques osteopaths employ, they offer a superficial understanding of practitioners' clinical practice and decision-making.

Over the last forty years researchers have been attempting to understand the nature and processes of clinical practice and decision-making. For example, in the physiotherapy profession there is a growing body of research on a range of aspects of practice such as the processes of clinical decision-making (Edwards et al., 2004; Cruz et al., 2012) and the nature and development of expertise (Jensen et al., 2000; Petty et al., 2011a,b). This research 

demonstrates that well-developed clinical decision-making skills arefundamental to expertise(Jensen etal., 2008). There is currently little-to-no research of osteopaths' clinical decisions-making and their approaches to practice (Thomson et al., 2011). A researchbased knowledge of these areas of osteopathy would be valuable to educators and practitioners and ultimately help enhance patient care. The aim of this study was to develop an explanatory theory of the clinical decision-making and therapeutic approaches of experienced osteopaths in the UK.

\section{Methods}

\subsection{Study design}

The study used constructivist grounded theory (Charmaz, 2006). By exploring the different meanings and experiences of clinical practice and decision-making raised by participants, the main researcher (OT) co-created the data and ensuing analysis through an interactive process, and developed an "interpretive portrayal" (Charmaz, 2006, p. 10) of participants' views, perceptions and experiences.

\subsection{Participants}

Twelve UK registered osteopaths took part in this study. Recruitment adverts placed in osteopathic educational institutions (OEIs) and the osteopathic press nationally, invited practitioners to contact OT should they wish to take part in the study. Upon initial contact, practitioners were provided with information and given the opportunity to ask any questions regarding the study. Having then expressed a wish to participate, details of practitioners' professional background (e.g. teaching/clinical experience, education, interests/ specialities) were obtained and a list of potential participants was compiled. From this list, purposive sampling initially selected practitioners with a minimum of five years clinical experience, and currently held positions as clinical educators at an OEI. Clinical educators were expected to effectively communicate and verbalise their decision-making processes (Ajjawi and Higgs, 2008), enabling 'thick' data to be generated and enhance the credibility of the research findings (Lincoln and Guba, 1985). Subsequent theoretical sampling (Charmaz, 2006), informed by data analysis, led to specific participants being re-interviewed as well as additional participants being sampled who were not involved with osteopathic education. Table 1 provides participants' biographical information.

Each practitioner gave informed consent before participating. All patients gave informed consent before commencing each observation session.

\subsection{Data collection and analysis}

Inline with the iterative nature of grounded theory, data collection and analysis occurred concurrently (Charmaz, 2006). A total of seventeen semi-structured interviews were transcribed verbatim, read/re-read and analysed throughout the course of the study. During the data collection process, the interview guide became progressively focused so that concepts constructed from data analysis could be pursued and ideas explored (Table 2). Data was initially collected from interviews with nine participants (P1e9). Three participants (P6e8) were theoretically sampled and re-interviewed as they each exhibited strong characteristics of the therapeutic approaches which were developing from analysis. As the study approached theoretical sufficiency (Charmaz, 2006), a further three participants (P10e12) were observed and videorecorded during a patient appointment, which was followed by a video-prompted reflective interview (Haw and Hadfield, 2011).
Table 1

Biographical information of study participants.

\begin{tabular}{|c|c|c|c|c|}
\hline Participant & Gender & $\begin{array}{l}\text { Years } \\
\text { since } \\
\text { graduating }\end{array}$ & Qualifications & $\begin{array}{l}\text { Teaching position } \\
\text { held }\end{array}$ \\
\hline 1 & M & 13 & BSc (Hons) Ost & $\begin{array}{l}\text { Clinic tutor and } \\
\text { lecturer }\end{array}$ \\
\hline 2 & M & 14 & $\begin{array}{l}\text { BSc (Hons) Ost Med, } \\
\text { Dip Ost }\end{array}$ & $\begin{array}{l}\text { Clinic tutor and } \\
\text { lecturer }\end{array}$ \\
\hline 3 & M & 6 & $\begin{array}{l}\text { BSc (Hons) Ost Med, } \\
\text { Dip Ost, MSc }\end{array}$ & $\begin{array}{l}\text { Clinic tutor and } \\
\text { lecturer }\end{array}$ \\
\hline 4 & M & 16 & Dip Ost & $\begin{array}{l}\text { Clinic tutor and } \\
\text { lecturer }\end{array}$ \\
\hline 5 & $\mathrm{~F}$ & 13 & $\begin{array}{l}\text { BSc (Hons) Ost Med, } \\
\text { Dip Ost }\end{array}$ & Clinic tutor \\
\hline 6 & M & 25 & $\begin{array}{l}\text { BSc (Hons) Ost Med, } \\
\text { Dip Ost, MSc }\end{array}$ & $\begin{array}{l}\text { Clinic tutor and } \\
\text { lecturer }\end{array}$ \\
\hline 7 & M & 9 & $\begin{array}{l}\text { BSc (Hons) Ost, Med, } \\
\text { Dip Ost, } \\
\text { Dip Naturopathy, } \\
\text { MSc }\end{array}$ & Lecturer \\
\hline 8 & M & 22 & $\begin{array}{l}\text { BSc (Biochem) } \\
\backslash \text { Dip Ost }\end{array}$ & Clinic tutor \\
\hline 9 & $\mathrm{~F}$ & 22 & $\begin{array}{l}\text { BSc (Hons) Ost Med, } \\
\text { Dip Ost, } \\
\text { Dip Naturopathy }\end{array}$ & $\begin{array}{l}\text { Clinic tutor and } \\
\text { lecturer }\end{array}$ \\
\hline 10 & M & 6 & $\begin{array}{l}\text { BSc (Hons) Psych, } \\
\text { BSc (Hons) Ost Med, } \\
\text { Dip Ost, MSc }\end{array}$ & None \\
\hline 11 & M & 14 & $\begin{array}{l}\text { BA, BSc (Hons) Ost, } \\
\text { Dip Ost, }\end{array}$ & $\begin{array}{l}\text { Clinic tutor and } \\
\text { lecturer }\end{array}$ \\
\hline 12 & M & 19 & BSc Ost & None \\
\hline
\end{tabular}

OEI: Osteopathic Educational Institution; BSc: Bachelor of Science; DO: Diploma in osteopathy; MSc: Master of Science.

Non-participant observations of 'real-life' patient appointments enabled the researcher to compare the similarities and differences between the 'espoused theory' generated during interviews with 'theory-in-action' (Argyris and Schön, 1974). An observation guide (Table 3) enabled OT to make theoretical connections between what previous participants had said during interviews with what was observed during clinical sessions, providing further analytical insights. The video-recording deepened participants reflection during interviews, helping to ensure discussion were closely tied to participants' actions and decisions, which took place during the clinical appointment (Haw and Hadfield, 2011). Towards the end of the study two participants $(\mathrm{P} 1,10)$ were theoretically sampled and re-interviewed to explore and test out the proposed core category of 'conception of practice' (Fish and Coles, 1998) and further develop the theory. The major analytical processes used were:

\subsubsection{Coding}

The active construction of codes during analysis formed a link between data collection and development of the theory and helped explain and understand conceptual reoccurrences and patterns in the data (Birks and Mills, 2011). During the early stages of analysis initial line-by-line coding (Charmaz, 2006) was employed to define actions or events of a given situation. Focused coding, was then used to assess which codes appeared to be the most significant (Charmaz, 2006). This led to the development of new focused codes which were used to analyse larger segments of data. This process elevated the level of conceptual analysis so that broader categories could be developed.

\subsubsection{Constant comparative analysis}

This involved comparing data with data, data with category, category with category (Charmaz, 2006). Constant comparison was used throughout data analysis, from initial coding to advanced levels of analysis when writing up the findings. 
Table 2

Interview guides for initial, video-prompted reflective and theoretically sampled participant interviews.

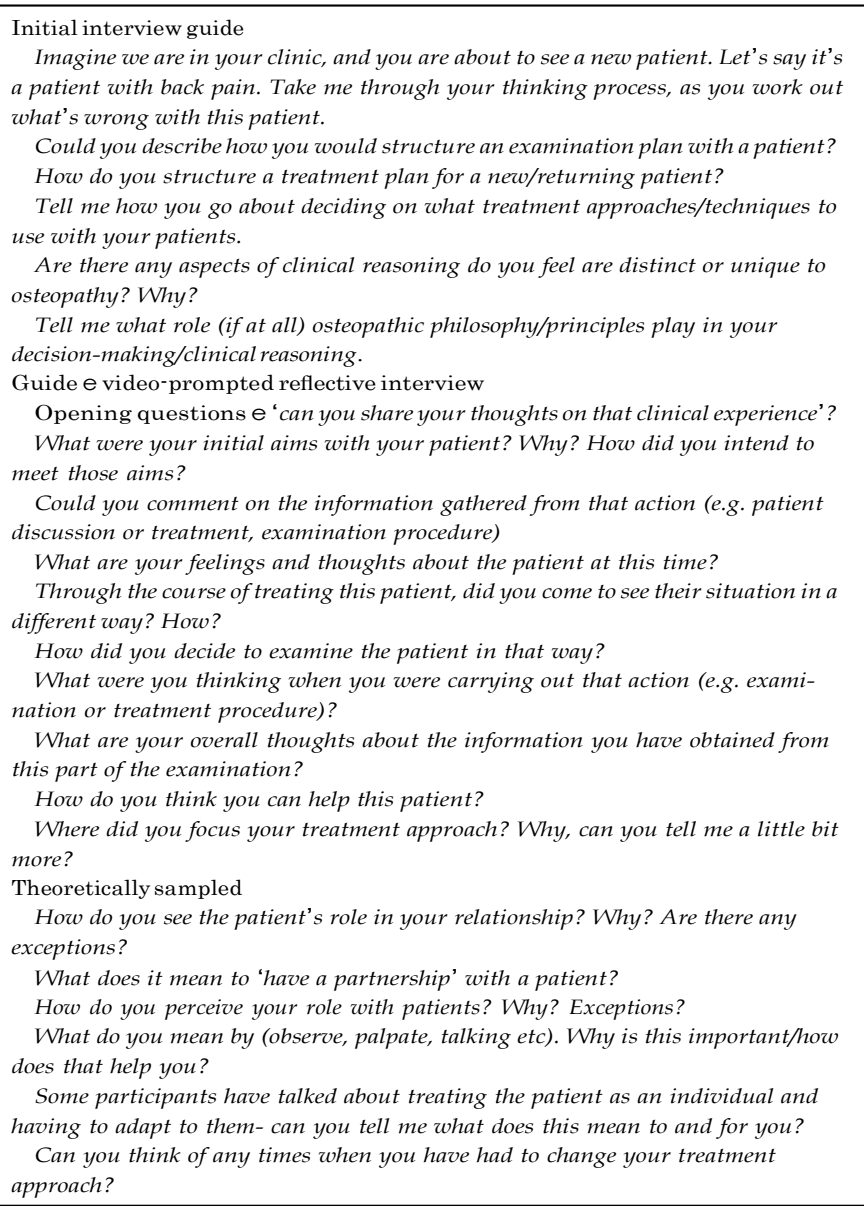

\subsubsection{Memo-writing}

Memo-writing throughout the data collection, coding and categorisation processes encouraged critical reflexivity, and helped link data-gathering with analysis. Memo-writing enabled the identification of codes, patterns and relationships in the data so that codes could be defined and grouped to form categories with an increasing level of conceptual abstraction. Identifying the characteristics and properties of categories helped give them shape and multidimensionality. Importantly, developing properties of categories though memo-writing, facilitated the identification of gaps

Table 3

Observation guide used during video-recorded clinical observation sessions.

Observation guide

- How does the interaction of patient and osteopath begin? How does the interaction proceed?

- The approach that the particular osteopath takes to examination and treatment, with the three types of practice approaches in mind (Treater, Communicator and Educator). How do they personalise these?

- The role that the patient takes in the encounter, for example, is the patient actively engaging and participating or taking a more passive approach?

Has the osteopath come across something new or unfamiliar/unexpected, how does he react?

- During the 'hands-on' osteopathic treatment what is the verbal and nonverbal interaction like?

- Are there any tonal changes of voice?

- What is the body language, body reactions and responses of participants?

- Types of questions asked (e.g. open questions or closed questions?), and the response of the patient.

- What does the practitioner focus the conversation on? in the developing theory, which informed further data analysis and theoretical sampling (Charmaz, 2006).

\subsection{Trustworthiness}

A prolonged engagement with the data (three years) and repeated interactions and interviews with participants contributed towards the credibility of this research (Lincoln and Guba, 1985). The researcher was an osteopath with clinical experience and knowledge and pre-existing awareness/knowledge of five of the twelve participants. During data collection, OT actively sought to develop a trustful researchereparticipant relationship, which facilitated participants' sharing of their views and experiences of clinical practice. These strategies helped to offset participant bias and enhance data credibility.

A process of 'member-checking' (Bryman, 2008) was used; all participants were asked to read their interview transcript to check for accuracy, and were encouraged to add further comments that they felt necessary.

Finally, throughout the study, OT maintained a critically reflexive stance, wrote copious field notes, memos and kept a reflexive diary. These methods of reflexivity aimed to offset researcher bias and meant that any feelings, assumptions or analytical thoughts that arose could be put into writing then tested and checked-out with the data (Cutcliffe, 2003).

\section{Findings}

The clinical decision-making and therapeutic approaches of the osteopaths in this study are illustrated fully in the explanatory model (Fig. 1). Analysis of data generated during interviews with participants and observation of their clinical practice resulted in the construction of six major categories, these were participants':

- view of osteopathy

- interaction with patients and interpretation of cues

- approach to clinical decision-making and level of patient involvement

- therapeutic goal

- conception of practice

- therapeutic approach

Each category is presented in turn and supported by quotations from participants' interview data. A more detailed discussion of the findings can be found elsewhere (Thomson, 2013).

\subsection{View of osteopathy}

There was variation in how participants described their practise of osteopathy. For several participants $(\mathrm{P} 1,2,5,8,11,12)$ the central feature of osteopathy was their application of specific osteopathic theories, knowledge and hands-on skills, suggesting a practitionercentred view of osteopathy:

You need to keep pure to osteopathic philosophy. [and] the principles of osteopathy make me do what I do.

Others valued working with patients so that decisions were made together $(\mathrm{P} 3,4,7)$. These participants emphasised collaboration and partnership with patients, respecting them as equals:

I don't cure patients. Together we work out how come to a better state of health. 


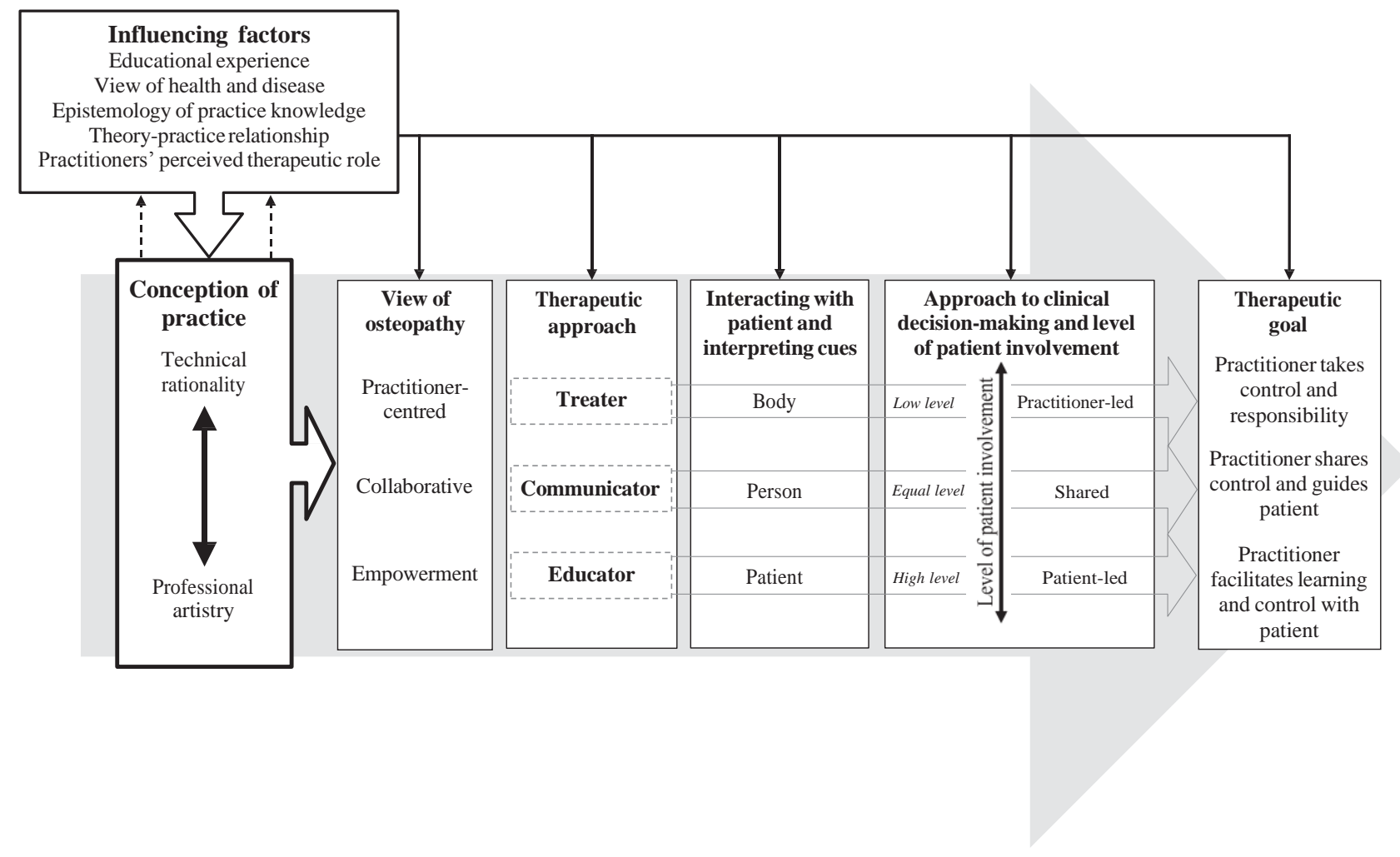

Fig. 1. Theory of the clinical decision-making and therapeutic approaches of study participants.

Finally, some participants viewed osteopathy as a means by which they could facilitate patient empowerment $(\mathrm{P} 6,9,10)$. These participants could not separate patient empowerment from their practise of osteopathy, and facilitating patient-learning was central to their treatment and management interventions:

I really believe in patient autonomy, I think patients are responsible for themselves... it gives them control.

ee(P6)

\subsection{Interacting with patients and interpreting cues}

During clinical procedures (e.g. clinical assessment), participants' focus of interaction with patients, and the cues generated and interpreted from this interaction varied. Body-focused interaction enabled some participants $(\mathrm{P} 1,2,5,8,11,12)$ to obtain knowledge and understanding of patients' bodies and physical problems:

I use my palpation to assess and let the body tell me what it wants me to do, and will permit me to do.

ee $(\mathrm{P} 1)$

As I watched the active shoulder movements I'm looking at areas of his back which are most restricted.

ee(P11)

I like spending time talking to the person about what's going on and how it's impacting them.

We take time to sit down, talk and make sure that he understands what's going on and what he can and can't do to improve it.
The first two quotes suggest a body-focused interaction where the clinical gaze was fixed upon the biomechanical and physical characteristics of patients' bodies (P1,2,5,8,11,12). Moving, touching and observing the body was central in acquiring cues.

The third quote suggests a person-focused interaction which involved talking and listening, to construct knowledge of the patient as a person. These participants $(\mathrm{P} 3,4,7)$ focused their interaction on patients' personal experiences of pain and dysfunction.

The final quote suggests a patient-focused interaction where talking and listening enabled the participant to learn from patients. These participants $(\mathrm{P} 6,9,10)$ tended to explore patients' day-to-day function, their preferences of treatment and management interventions.

\subsection{Approach to clinical decision-making and level of patient involvement}

There was variation in the level of patient involvement in treatment and management strategies which was related to participants' approaches to clinical decision-making and therapeutic goals (Fig. 2). The three different approaches to clinical decisionmaking were; practitioner-led (low-level of patient involvement), shared (equal-level of patient involvement) and patient-led (highlevel of patient involvement).

Participants taking a practitioner-led approach to decisionmaking emphasised a low-level of patient involvement $(\mathrm{P} 1,2,5,8,11,12)$. They led the clinical decision-making and tended not to encourage active patient involvement and input:

I'll determine what [treatment] techniques I think the patient needs. 


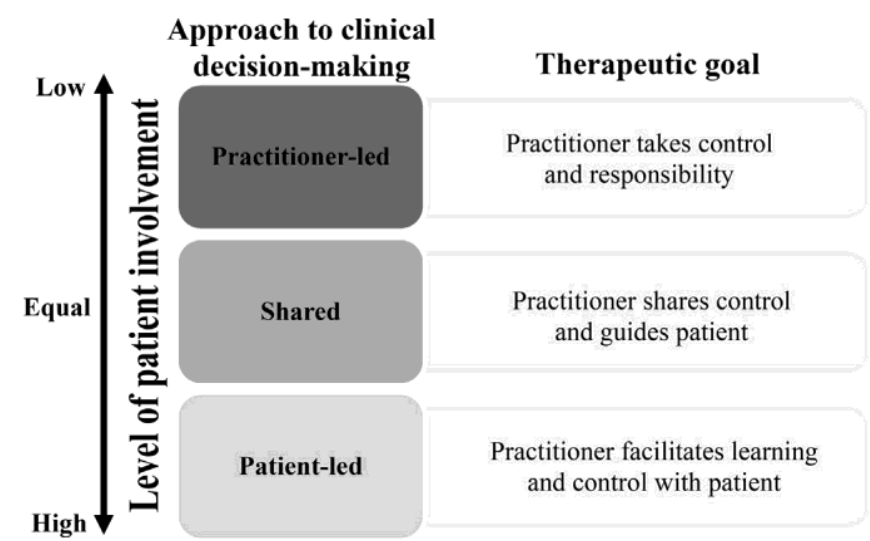

Fig. 2. Relationship between level of patient involvement, approach to clinical decision-making and therapeutic goal.

Whereas, other participants $(\mathrm{P} 3,4,7)$ encouraged shared decision-making with patients, promoting collaboration and an equal-level of patient involvement:

We've tried many different interventions,...[and] we've talked through options together.

ee(P10)

Some participants $(\mathrm{P} 6,9,10)$ adopted a patient-led approach to clinical decision-making and facilitated high-levels of patient involvement. These participants encouraged patients to take the lead in decision-making and educated patients so that they could make informed decisions:

...my process is "do you have any preference, what would you like, what do you think would help you most?" "Now that you've chosen, these are the side-effects. Are they acceptable?

ee(P6)

\subsection{Therapeutic goal}

Participants expressed a range of therapeutic goals which were related to their approach to clinical decision-making and level of patient involvement (Fig. 2). Several participants (P1,2,5,8,11,12) emphasised goals orientated towards them taking control and responsibility of patients' problems, and encouraging patient passivity:

...treatment is a time for patients to relax...[and] to have the treatment.

Other participants aimed to guide patients towards their personal goals $(\mathrm{P} 3,4,7)$. This meant at times, participants would lead decision-making, but at other times they encouraged patients to adopt more active approaches:

I'll take time to discuss what the options are with patients, I'll say, "this is what I can do and this is what you can do".

Whereas other participants $(\mathrm{P} 6,9,10)$ emphasised the importance of patients to control the possible directions that treatment and management could take. These participants aimed to facilitate learning and control with patients:

I always try and empower my patients...to feel in control.

\subsection{Conception of practice}

Conception of practice was considered to be how participants viewed the nature of their practice and this was closely associated with their views on the nature of knowledge associated with their practice; this has been explicated by various authors (Schön, 1987; Fish, 1998; Fish and Coles, 1998) in relation to technical rationality and professional artistry. Conception of practice was selected as the core category of the explanatory theory, as it helped to organise the categories into a process and explained the variations in the data (Charmaz, 2006). It is explored in detail elsewhere (Thomson, 2013; Thomson et al., 2013). Participants that conceived practice as technical rationality $(\mathrm{P} 1,2,5,8,11,12)$ considered practice as involving the straightforward application of propositional knowledge:

...my practice is based on genuine biomechanical principles...[and] manual provocation techniques to reproduce patients' symptoms.

ee(P5)

They sought to establish causeeeffect relationships and emphasised technical expertise and hands-on skills during clinical practise:

If the patient was complaining of posterior thigh pain, I want to determine what I think the structure is and where it's being compromised.

ee(P8)

Whereas, those participants that conceived practice as professional artistry (P3,4,6,7,9,10) viewed practice as complex, dynamic and appreciated different sources and forms of knowledge, which were blended together to guide clinical action:

I put all of the information obtained from the examination with patient expectation, the relationship that I have with them and I draw on all of it to point us in the right direction.

ee(P10)

Five factors were identified which influenced participants' conception of practice, and help to explain their therapeutic approach and clinical decision-making (Table 4).

\subsection{Therapeutic approach}

Three theoretical models of therapeutic approaches characterised study participants and their clinical practice. This is not to suggest that all participants fitted distinctly in each model, rather it offers a broad differentiation of participants' therapeutic approach to allow for theoretical comparison. Fig. 3 illustrates the continuum of conception of practice and its relationship with participants' therapeutic approaches, level of patient involvement and approach to clinical decision-making.

\subsubsection{The Treater}

Treaters (P1,2,5,8,11,12) had a view of osteopathy which was practitioner-centred, and they relied upon their application of specialised osteopathic skills, technical expertise and knowledge to diagnose, treat and manage patients. They appeared less flexible in their clinical approach, and felt that the application of traditional osteopathic theories and concepts was central to their practice, and was important to distinguish them from other healthcare professionals. They focused on patients' physical and biological dysfunction and how they could correct these through hands-on treatment:

My primary aim is to treat, rather than 'let's sit down and discuss your problem and see what we can do about it'. 
Table 4

Factors and properties which influenced participants' conception of practice.

\begin{tabular}{|c|c|c|}
\hline Influencing factor & Technical rationality & Professional artistry \\
\hline Educational experience & $\begin{array}{l}\text { Teacher-centred, uncritically accepting } \\
\text { knowledge } \\
\text { I still use the principles that I was taught } \\
\text { as a student [and] they are still very relevant to me. (P1) }\end{array}$ & $\begin{array}{l}\text { Student-centred, critically constructing knowledge } \\
\text { Through reflection and time you begin to scrutinise } \\
\text { things more and reject those fads and formulate your } \\
\text { own ideas about osteopathy. (P3) }\end{array}$ \\
\hline View of health and disease & $\begin{array}{l}\text { Biomedical: reduce patients' problem } \\
\text { down in a specific tissue or body structure } \\
\text { and separates it from their social and } \\
\text { emotional circumstances } \\
\text { If you don't have the basics like anatomy and } \\
\text { physiology you are never going to get the } \\
\text { right decision. (P12) }\end{array}$ & $\begin{array}{l}\text { Biopsychosocial: considered patients' problem in } \\
\text { the context of their lives and their illness experience } \\
\text { I like to see the other factors that would be influencing } \\
\text { the way that they [the patient] experience } \\
\text { their problem...it gives you a much rounder picture } \\
\text { of the person you're treating. (P6) }\end{array}$ \\
\hline $\begin{array}{l}\text { Epistemology of practice } \\
\text { knowledge }\end{array}$ & $\begin{array}{l}\text { Positivist-post-positivist: Focused on cause-effect } \\
\text { relationships, knowledge is stable and factual } \\
\text { If somebody's got left-sided low back pain and } \\
\text { their pelvis tilts down to the right then the structures } \\
\text { will be more compressed on that left side. (P8) }\end{array}$ & $\begin{array}{l}\text { Constructionist: listening and using language to develop an understanding } \\
\text { of how patients' made sense of their problem } \\
\text { I seem to talk so much to patients, as I find that talking opens up a deeper } \\
\text { level of understanding for them and me. (P3) }\end{array}$ \\
\hline Theory-practice relationship & $\begin{array}{l}\text { Theories applied to practice: view theory as separate } \\
\text { from practice, apply existing theories (biomechanical } \\
\text { and osteopathic theories) to practice. } \\
\text {...my practice is based on genuine biomechanical } \\
\text { stuff[theories]. (P5) }\end{array}$ & $\begin{array}{l}\text { Theories developed from practice: Though learning from, and reflecting on, } \\
\text { practice they would develop their own personalised theories and } \\
\text { practice models. } \\
\text { I'm getting away from "I've got to get my hands on and get them better" to "right, } \\
\text { this is the situation and this is how we can approach it; it's your decision, } \\
\text { what would you like to do?" So [my approach] has become much } \\
\text { more collaborative. (P6) }\end{array}$ \\
\hline $\begin{array}{l}\text { Practitioner's perceived } \\
\text { therapeutic role }\end{array}$ & $\begin{array}{l}\text { Paternalism: assuming responsibility for } \\
\text { the decision-making } \\
\text { I am trying to get a little bit of mobility for him. } \\
\text { To increase that range [of motion] for him, } \\
\text { so that does not hold on to the joint so that } \\
\text { he actually lets go of it. (P11) }\end{array}$ & $\begin{array}{l}\text { Patient autonomy: Patient as an active partner, views, knowledge } \\
\text { and expectations exchanged and decisions negotiated } \\
\text { By giving patients choice it treats them as an adult and gives them } \\
\text { the autonomy. (P6) }\end{array}$ \\
\hline
\end{tabular}

Treaters analysed patients' bodies and tissues, and in combination with their osteopathic knowledge and technical expertise, they diagnosed and led the decision-making based on logical connections between anatomy, physiology and biomechanics. In this sense, Treaters conceived practice as technical rationality.

\subsubsection{The Communicator}

For Communicators $(\mathrm{P} 3,4,7)$ collaboration and partnership formed the foundations of their view of osteopathy. They respected patients as equals, viewing them as individuals. Communicators focused on language and dialogue to encourage patients to verbalise their feelings and experiences about their problem. They placed significant value on developing and nurturing an equal relationship with their patients. Through talking and listening, Communicators conceived practice as professional artistry, and relied upon their interpersonal skills to interact and engage

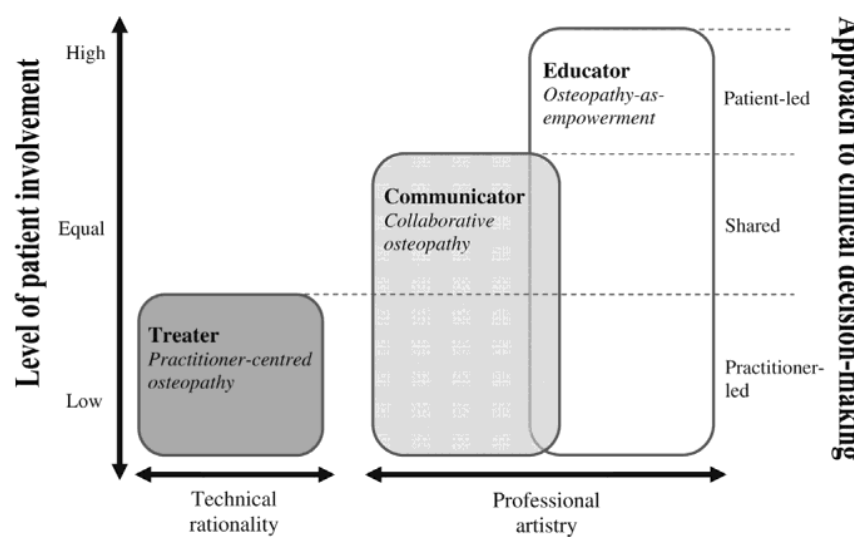

Conception of practice

Fig. 3. Therapeutic approaches and the conception of practice continuum. patients and help guide their clinical decision-making and professional judgements:

I would judge treatment by how I relate to the patient personally.

Communicators shared the responsibility of clinical decisionmaking with their patients, resulting in treatment and management decisions being mutually negotiated.

\subsubsection{The Educator}

Educators $(\mathrm{P} 6,9,10)$ worked with patients to develop the skills to self-manage their health issue, looking to facilitate empowerment. They focused on teaching and motivating patients to enable them to manage their own pain and dysfunction. Educators emphasised listening and learning from their patients, and they were focused on building an understanding of patients' problems and how it impacted their function in day-to-day life so that patient-specific treatment plans could be developed:

I see the patient as an individual who owns their own body and can make decisions about it.

Educators saw their role to encourage, teach, and exchange knowledge so that patients were active and informed decisionsmakers about their treatment and management. By learning from their patients and their practice they developed their own personal theories of practice and treatment approaches, which were facilitated by their professional artistry conception of practice.

\section{Discussion}

The findings from this study suggest that participants held differing views of the purpose and practise of osteopathy. How these views and assumptions of osteopathy were enacted, shaped 
practitioners' clinical actions, decisions and resulted in different therapeutic approaches to practice (Trede and Higgs, 2008). The findings that there is diversity in how practitioners identify with their profession and their conceptions of being a professional is consistent with research in physiotherapy (Öhman and Hägg, 1998; Richardson et al., 2002; Lindquist et al., 2006).

This study found that differences in therapeutic approach led to variation in the focus of participants' interaction with their patients and the cues they generated and interpreted. Practitioners' conceptions of practice (Fish and Coles, 1998) and the assumptions and beliefs that they hold about the body (Thornquist, 1994, 2006) influence what they 'see', how they see 'it' and their resulting decision-making and action. While all participants' assessment of their patients involved case-history taking and clinical examination, there was variation in their "gaze" (Thornquist, 1994, p. 9) during these clinical procedures. This resulted in diversity regarding what clinical information participants found relevant, and where and how they focused their interaction with patients to generatecues.

The findings suggest that clinical decision-making in osteopathy occurs with varying levels of patient involvement and is related to practitioners' therapeutic approach. Participants characterised as Treaters-adopted practitioner-led approaches to clinical decisionmaking. This approach was associated with minimal patient involvement, and is consistent with 'paternalistic' models of decision-making (Emanuel and Emanuel, 1992). The determination of these participants to obtain information from the patient's body through skilled physical analysis and examination placed little priority on exchanging or sharing information with patients, implying an 'all-knowing' practitioner (Emanuel and Emanuel, 1992). Whilst the hands-on skills and technical expertise of osteopaths may lead to high degrees of patient satisfaction, an approach which promotes patient passivity may encourage patients to adopt a 'sick role', and risk them becoming dependant on passive manual therapy treatment (Beisecker and Beisecker, 1993). An approach to decision-making which fails to consider patients' perceptions and expectations may not help develop a patient's sense of control over their problem (Klaber Moffett and Richardson, 1997) and miss a valuable opportunity to enhance their self-efficacy (Bandura, 1982). Patients' illness perceptions, self-efficacy beliefs and catastrophising of their symptoms, have been identified as psychological obstacles to recovery of low back pain (Foster et al., 2010; Grotle et al., 2010); therefore osteopaths should endeavour to acknowledge these factors and facilitate their exploration in relation to their patients.

The findings indicate that participants characterised as Communicators shared their clinical decision-making with patients and encouraged an equal-level of patient involvement. This is consistent with shared models of decision-making in the medical literature (Ballard-Reisch, 1990; Charles et al., 1999) and with research in musculoskeletal physiotherapy (Jensen et al., 2000; Edwards et al., 2004). Sharing clinical decisions emphasises patients as active partners, and involves both individuals contributing knowledge and skills so that decisions can be mutually negotiated together (Charles et al., 1999).

Participants who were characterised at Educators adopted a patient-led approach to clinical decision-making and advocated high-levels of patient involvement, analogous to the 'informed choice' (Gafni et al., 1998) and 'consumerism' models of decisionmaking (Emanuel and Emanuel, 1992). These participants encouraged patients to express their own views on their problem and preferences for possible treatment options, thereby providing a channel for patients to exercise control, thus facilitate empowerment (Ramsay Wan et al., 2012), and enhance self-efficacy (Bandura, 1982).
The finding that some practitioners adopt practitioner-centred approaches may not be congruent with shared models of decision-making promoted by the osteopathic regulator (GOsC, 2012a) and more widely by the NHS (DoH, 2012). Active patient involvement in decision-making is now widely considered fundamental (Charles et al., 1997; Entwistle and Watt, 2006; DoH, 2012) and is harmonious with conceptions of patient-centred care (Mead and Bower, 2000; Stewart, 2001). As almost 90\% of patients selffund their osteopathic services (GOsC, 2012c), practitioners may consider that a paternalistic approach to care, best-serves their 'customer'. However, if some osteopaths are not promoting shared models of decision-making in their private practice, then this may present difficulties for future opportunities of integration and collaboration within the public healthcare sector, where shared models of decision-making are currently promoted (DoH, 2012).

\subsection{Study limitations}

The explanatory theory developed from this study provides the first research-based model of clinical decision-making and therapeutic approaches in osteopathy. The findings offer a number of theoretical insights into the clinical practice of osteopaths which may have value to practitioners and educators of osteopathy and different manual therapy professions. However, the reader is reminded that the researcher co-constructed and co-created the findings from this study with a sample of privately practicing experienced osteopaths in the UK. Further research is necessary to establish the 'reach' of the substantive theory for example with osteopaths in other countries, practitioners and with less experience.

\section{Conclusion}

Experienced osteopaths in this study adopted a variety of therapeutic approaches in their clinical practice which influenced their interaction with patients, clinical decision-making, level of patient involvement and therapeutic goal. Participants' therapeutic approaches flowed from how they conceived their practice. Participants' overall conception of practice lay on a continuum, from technical rationality to professional artistry. A number of factors were identified which influenced practitioners' conception of practice and help explain their therapeutic approach and clinical decision-making. This study offers the first explanatory theory of the clinical decision-making and therapeutic approaches of osteopaths.

\section{Ethical approval}

Ethical approval was granted by the research ethics committees at the University of Brighton and the British College of Osteopathic Medicine.

\section{Acknowledgements}

Thanks to the British College of Osteopathic Medicine and the Osteopathic Educational Foundation for their support of this doctoral research.

\section{References}

Ajjawi R, Higos J. Learning to communicate clinical reasoning In: Higgs J, Jones M Loftus S, Christensen N, editors. Clinical reasoning in the health professions. 3rd ed. Amsterdam: Butterworth-Heinemann; 2008.

Argyris C, Schön DA. Theory in practice: increasing professional effectiveness. Jossey-Bass; 1974.

Ballard-Reisch DS. A model of participative decision making for physicianepatient interaction. Health Communication 1990;2:91e104. 
Bandura A. Self-efficacy mechanism in human agency. American Psychologist 1982;37:122.

Beisecker AE, Beisecker TD. Using metaphors to characterize doctorepatient relationships: paternalism versus consumerism. Health Communication 1993;5: $41 e 58$.

Birks M, Mills J. Grounded theory: a practical guide. Los Angeles, Calif., London: Sage; 2011.

Bryman A. The nature of qualitative research. In: Bryman A, editor. Social research methods. 3rd ed. Oxford: Oxford University Press; 2008. p. 365e99.

Charles C, Gafni A, Whelan T. Shared decision-making in the medical encounter: what does it mean? (or it takes at least two to tango). Social Science \& Medicine 1997.

Charles K, Gafni A, Whelan T. Decision-making in the physicianepatient encounter: revisiting the shared treatment decision-making model. Social Science \& Medicine 1999.

Charmaz K. Constructing grounded theory. London, Thousand Oaks, Calif.: Sage Publications; 2006.

Cruz EB, Moore A, Cross V. Clinical reasoning and patient-centred care in musculoskeletal physiotherapy in Portugal e a qualitative study. Manual therapy 2012;17:246e50.

Cutcliffe JR. Reconsidering reflexivity: introducing the case for intellectual entrepreneurship. Qualitative Health Research 2003;13:136e48.

DoH (Department of Health). Liberating the NHS: no decision about me, without me. London: Department of Health; 2012.

Edwards I, Jones M, Carr J, Braunack-Mayer A, Jensen GM. Clinical reasoning strategies in physical therapy. Physical Therapy 2004;84:312e30.

Emanuel EJ, Emanuel LL. Four models of the physicianepatient relationship. JAMA 1992;267:2221e6.

Entwistle VA, Watt IS. Patient involvement in treatment decision-making: the case for a broader conceptual framework. Patient Education and Counseling 2006;63:268e78

Fawkes C, Leach J, Mathias S, Moore AP. Standardised data collection within osteopathic practice in the UK: development and first use of a tool to profile osteopathic care in 2009. National Council for Osteopathic Research: University of Brighton; 2010.

Fish D. Appreciating practice in the caring professions: refocusing professional development and practitioner research. Oxford: Butterworth-Heinemann 1998.

Fish D, Coles C. Developing professional judgement in health care: learning through the critical appreciation of practice. Oxford, Boston: Butterworth-Heinemann 1998

Foster NE, Thomas E, Bishop A, Dunn KM, Main CJ. Distinctiveness of psychological obstacles to recovery in low back pain patients in primary care. PAIN 2010;148: $398 \mathrm{e} 406$.

Gafni A, Charles C, Whelan T. The physicianepatient encounter: the physician as a perfect agent for the patient versus the informed treatment decision-making model. Social Science \& Medicine 1998.

GOsC (General Osteopathic Council). Osteopathic practice standards. London General Osteopathic Council; 2012a.

GOsC (General Osteopathic Council). Osteopathy in practice. London: General Osteopathic Council; 2012b.

GOsC (General Osteopathic Council). Surveys \& statistics. London: General Osteopathic Council; 2012c.

Grotle M, Foster NE, Dunn KM, Croft P. Are prognostic indicators for poor outcome different for acute and chronic low back pain consulters in primary care? Pain 2010;151:790e7.

Hartman L. Handbook of osteopathic technique. Nelson Thornes; 1996.

Haw K, Hadfield M. Video in social science research: functions and forms. Rutledge;

Hebgen E. Visceral manipulation in osteopathy. Thieme International; 2010.
Jensen G, Rensik L, Haddad A. Expertise and clinical reasoning. In: Higgs J, Jones M, Loftus S, Christensen N, editors. Clinical reasoning in the health professions. 3rd ed. Oxford: Elsevier, Butterworth-Heinemann; 2008. p. 123e35.

Jensen GM, Gwyer J, Shepard KF. Expert practice in physical therapy. Physical Therapy 2000;80:28e43 discussion 4e52.

Johnson SM, Kurtz ME. Osteopathic manipulative treatment techniques preferred by contemporary osteopathic physicians. Journal of the American Osteopathic Association 2003;103:219e24.

Klaber Moffett JA, Richardson PH. The influence of the physiotherapist-patient relationship on pain and disability. Physiotherapy Theory and Practice 1997; $13: 89$ e96

Liem T, McPartland JM, Skinner E. Cranial osteopathy: principles and practice. Elsevier Science Health Science Division; 2004.

Lincoln YS, Guba EG. Naturalistic inquiry. Beverly Hills, Calif: Sage Publications; 1985.

Lindquist I, Engardt M, Garnham L, Poland F, Richardson B. Physiotherapy students' professional identity on the edge of working life. Medical Teacher 2006;28: $270 \mathrm{e} 6$.

Mead N, Bower P. Patient-centredness: a conceptual framework and review of the empirical literature. Social Science \& Medicine 2000;51:1087e110.

NICE. Low back pain: early management of persistent non-specific low back pain (clinical guideline 88). National Institute for Health and Clinical Excellence; 2009 .

Öhman A, Hägg K. Attitudes of novice physiotherapists to their professional role: a gender perspective. Physiotherapy Theory and Practice 1998;14:23e32.

Orrock P. Profile of members of the Australian Osteopathic Association: part 1 e the practitioners. International Journal of Osteopathic Medicine 2009;12:14e24.

Paulus S. The core principles of osteopathic philosophy. International Journal of Osteopathic Medicine; 2013 http://dx.doi.org/10.1016/j.ijosm.2012.08.003.

Petty NJ, Scholes J, Ellis L. The impact of a musculoskeletal masters course: developing clinical expertise. Manual therapy 2011a;16:590e5.

Petty NJ, Scholes J, Ellis L. Master's level study: learning transitions towards clinical expertise in physiotherapy. Physiotherapy 2011b;97:218e25.

Ramsay Wan C, Vo L, Barnes CS. Conceptualizations of patient empowerment among individuals seeking treatment for diabetes mellitus in an urban, publicsector clinic. Patient Education and Counseling 2012;87:402e4.

Richardson B, Lindquist I, Engardt M, Aitman C. Professional socialization: students' expectations of being a physiotherapist. Medical Teacher 2002;24:622e7.

Schön DA. Educating the reflective practitioner. 1st ed. San Francisco, CA: JosseyBass; 1987.

Seffinger M, King H, Ward R, Jones J, Rogers F, Patterson M. Osteopathic philosophy. In: Ward R, editor. Foundations for osteopathic medicine. 2nd ed. Philadelphia: Lippincott, Williams \& Wilkins; 2003. p. 3e18.

Stewart M. Towards a global definition of patient centred care. BMJ 2001;322:444

Thomson OP. Clinical decision making and therapeutic approaches of experienced osteopaths. University of Brighton; 2013. Unpublished $\mathrm{PhD}$ thesis.

Thomson OP, Petty NJ, Moore AP. Clinical reasoning in osteopathy e more than just principles? International Journal of Osteopathic Medicine 2011;14:71e6.

Thomson OP, Petty NJ, Moore AP. A qualitative grounded theory study of the conceptions of practice in osteopathy: a continuum from technical rationality to professional artistry. Manual Therapy; 2013 http://dx.doi.org/10.1016/j. math.2013.06.005.

Thornquist E. Varieties of functional assessment in physiotherapy. Scandinavian Journal of Primary Health Care 1994;12:44e50.

Thornquist E. Face-to-face and hands-on: assumptions and assessments in the physiotherapy clinic. Medical Anthropology 2006;25:65e97.

Trede F, Higgs J. Clinical reasoning and models of practice. In: Higgs J, Jones MA, Loftus S, Christensen N, editors. Clinical reasoning in the health professions. 3rd ed. Oxford: Elsevier, Butterworth-Heinemann; 2008. p. 31e41.

WHO. Benchmarks for training in osteopathy. Geneva: World Health Organization; 2010. 